\title{
Pemanfaatan sensor mikro DHT11-Arduino untuk monitoring suhu dan kelembaban udara
}

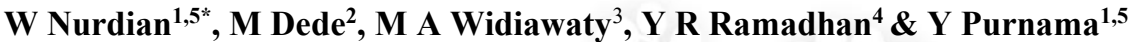 \\ ${ }^{1}$ Program Studi Teknik Informatika, Fakultas Teknik, Universitas Pelita Bangsa \\ ${ }^{2}$ Program Studi Magister Ilmu Lingkungan, Sekolah Pascasarjana, Universitas Padjadjaran \\ 3 Departemen Pendidikan Geografi, Fakultas Pendidikan Ilmu Pengetahuan Sosial, \\ Universitas Pendidikan Indonesia \\ ${ }^{4}$ Program Studi Meteorologi, Fakultas Ilmu dan Teknologi Kebumian, Institut Teknologi \\ Bandung \\ ${ }^{5}$ PT Tujuh Ion Indonesia, Cikarang, Kab. Bekasi \\ *e-mail : wikonurdian1995@gmail.com
}

\begin{abstract}
Climatic factors are an abiotic component that determines ecosystem characteristics. Rapid development activities require capable observation instruments and able to provide a variety of weather data to analyze their impact on the environment. This study aims to develop an instrument for measuring temperature and humidity as an essential component of climatic factors based on the DHT11-Arduino microsensor. Tests carried out at 30 scattered points in Cikarang Raya, Bekasi Regency, West Java. Data from the DHT11-Arduino microsensor measurement results are compared with the results of ground measurement and satellite imageries data in the same period through statistical tests. This research shows the DHT11-Arduino microsensor is able to measure temperature and humidity in Cikarang Raya with a significance level of $0.05-$ 0.01 . The correlation between microsensor and the comparative data in observing the temperature reached 0.934 , while the humidity reached 0.687. The distribution of temperature and humidity of the instruments shows a similar pattern. Using DHT11-Arduino microsensor to observe temperature and humidity has proven to be feasible and able developed to obtain climatic factors data as part of sustainable ecosystem management.
\end{abstract}

Key word : air humidity, climatic factors, DHT11-Arduino, microsensor, temperature.

\section{Pendahuluan}

Sistem kehidupan di permukaan bumi merupakan interaksi antar komponen yang membentuk geosfer. Bila merunut pada tingkatan yang lebih rendah, interaksi antar komponen tersebut direpresentasikan oleh ekosistem. Beragam makhluk hidup menjalin hubungan timbal balik dengan komponen abiotik dalam wujud aliran materi, energi, dan informasi [1]. Dewasa ini, komponen abiotik mengalami perubahan besar akibat intervensi manusia terhadap lingkungan yang dalam jangka panjang berpotensi menurunkan daya dukungnya. Salah satu komponen abiotik yang sangat dinamis adalah komponen cuaca dan iklim yang dikenal sebagai faktor klimatik. Beragam aktivitas antropogenik seperti industri, transportasi, dan rumah tangga mempengaruhi kondisi iklim mikro di sekitarnya 
yang dalam skala luas dapat menimbulkan perubahan iklim melalui mekanisme pemanasan global baik yang terjadi di daratan maupun lautan yang dalam 100 tahun terakhir telah meningkat sekitar $0,74^{\circ} \mathrm{C}[2,3]$.

Peningkatan suhu berkaitan dengan perkembangan wilayah urban. Alih fungsi lahan menyebabkan meningkatnya industrialisasi dan rasio peningkatan lahan terbangun di wilayah tertentu yang dikenal sebagai urban sprawl [4]. Pada ekosistem bervegetasi rapat, peningkatan suhu udara menyebabkan kelestarian dan keberlanjutannya terancam karena nilai klimogram berubah [5]. Kenaikan suhu bersifat multiplier effect terhadap beragam sektor, seperti pertanian, peternakan, dan perikanan [6]. Bahkan perubahan ini turut berdampak pada penyebaran endemi seperti demam berdarah, influenza, malaria, dan lain sebagainya [7]. Kenaikan suhu turut memicu peningkatan penggunaan energi untuk pendingin ruangan, sehingga konsumsi sumber daya untuk membangkitkan listrik turut meningkat. Beragam dampak peningkatan suhu mengindikasikan pentingnya peranan manusia dalam mempelajari dinamika cuaca dan iklim. Beragamnya unsur-unsur cuaca dan iklim dapat diamati melalui pengamatan dua unsur utamanya yakni suhu dan kelembaban udara. Suhu udara mempengaruhi laju evaporasi, evapotranspirasi, tekanan udara, dan sirkulasi angin, sedangkan kelembaban udara berpengaruh terhadap proses kondensasi atmosfer di sekitarnya [8]. Pengamatan keduanya dapat dilakukan melalui stasiun pengamatan cuaca yang umumnya memiliki kendala dari segi operasional, detail informasi, dan updating informasi, sedangkan bila menggunakan citra satelit maupun foto udara memiliki kendala dari segi resolusi spasial dan temporal [9].

Opsi untuk menangani permasalahan ini bisa dengan memanfaatkan sensor mikro yang terhubung dengan internet melalui skema Internet of Thing (IoT), sehingga dapat ditempatkan di lokasi tertentu sesuai kebutuhan pengguna. Sensor mikro yang dapat dikembangkan untuk mengukur parameter tersebut misalnya DHT11, DHT21, SHT21, HTU21, X2, dan lain sebagainya [10]. Mikro sensor memerlukan wahana untuk memproses pengambilan informasi, sehingga kehadiran kontroler mikro seperti Raspberry Pi maupun Arduino mutlak dibutuhkan [11]. Penelitian ini bertujuan untuk menguji penggunaan sensor mikro DHT11-Arduino untuk pengamatan suhu dan kelembaban udara di Cikarang Raya, Kabupaten Bekasi. Efektifitas sensor mikro DHT11-Arduino untuk mengukur dua parameter cuaca tersebut diuji secara spasial dengan hasil pengukuran lapangan (ground measurement) dan citra satelit multi-sensor pada periode yang sama.

\section{Metode Penelitian}

\subsection{Lokasi dan Waktu Penelitian}

Penelitian ini dilakukan pada periode musim kemarau tahun 2019 yang berlokasi di Cikarang Raya, Kabupaten Bekasi, Provinsi Jawa Barat. Secara geografis, Cikarang Raya berada pada $107^{\circ} 02^{\prime} 26.06 \mathrm{BT}-107^{\circ} 16^{\prime} 46^{\prime}$ " BT dan $6^{\circ} 13^{\prime} 54^{\prime \prime} \mathrm{LS}-6^{\circ} 23^{\prime} 54,33$ "LS yang meliputi lima kecamatan dengan 43 desa (Gambar 1). Pesatnya laju urbanisasi dan industrialisasi di Cikarang Raya merupakan salah satu alasan untuk menjadikannya sebagai lokasi penelitian. Dengan demikian, pengembangan sensor mikro ini diharapkan mampu peka terhadap variasi maupun faktor-faktor lokal yang mempengaruhi suhu dan kelembaban udara. Pada penelitian ini, mikro sensor diuji pada 26 titik pengamatan yang tersebar di seluruh wilayah kajian, dimana tiap titik pengamatan ditempatkan pada desadesa yang berbeda di Cikarang Raya. 


\subsection{Alat dan bahan}

Data suhu dan kelembaban udara diperoleh dari hasil pengukuran lapangan menggunakan sensor mikro DHT11-Arduino dan termometer manual/analog (TM). Data pembanding diperoleh dari analisis citra satelit multi-spektral Landsat-8 OLI dan Digital Elevation Model (DEM) berupa Shuttle Radar Topographic Maps (SRTM) 1 arc-second pada periode perekaman yang sama. Khusus untuk Landsat-8 OLI, analisis suhu menggunakan band (kanal) termal yakni kanal 11 dan kanal 12 yang dilengkapi dengan hasil analisis vegetation greenness (kerapatan vegetasi) melalui kombinasi kanal inframerah jarak dekat (NIR) dan kanal 4 (red). Pada kajian ini, istilah kelembaban udara hanya merujuk pada kelembaban relatif (relative humidity). Informasi selengkapnya mengenai akuisisi data penelitian tersaji pada Tabel 1.
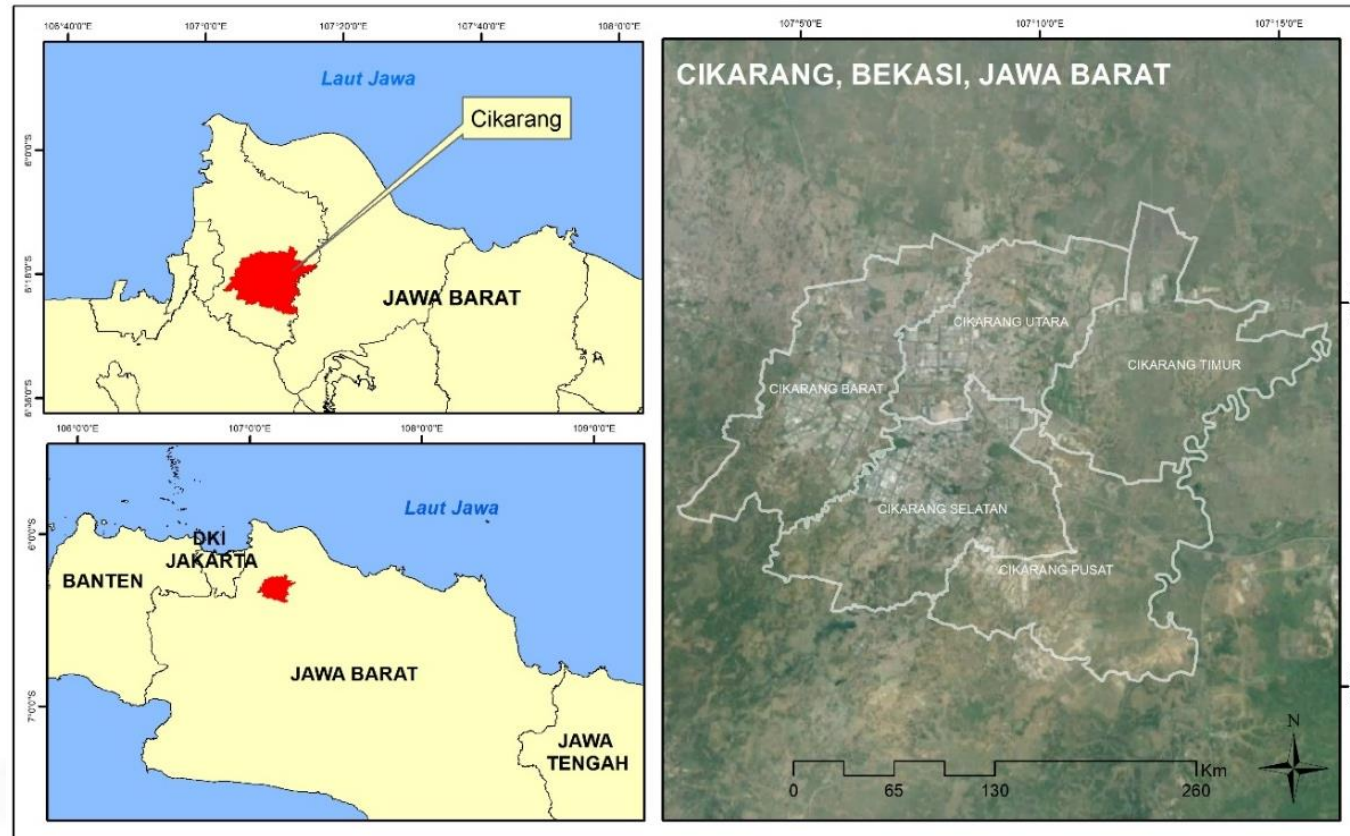

Gambar 1. Lokasi Kajian.

Analisis data suhu dan kelembaban udara menggunakan perspektif geospasial, sehingga seluruh data tersebut -kecuali kerapatan vegetasi- dianalisis dalam perangkat lunak sistem informasi geografis (SIG). Implikasinya data tersebut akan ditampilkan melalui isoline yakni garis atau gradasi warna sebagai tanda nilai yang sama, dimana untuk suhu dikenal sebagai isoterm dan kelembaban udara bernama isohume [12]. Interval data untuk masing-masing isoline menyesuaikan dengan variasi nilainya agar penyajiannya tetap informatif. 


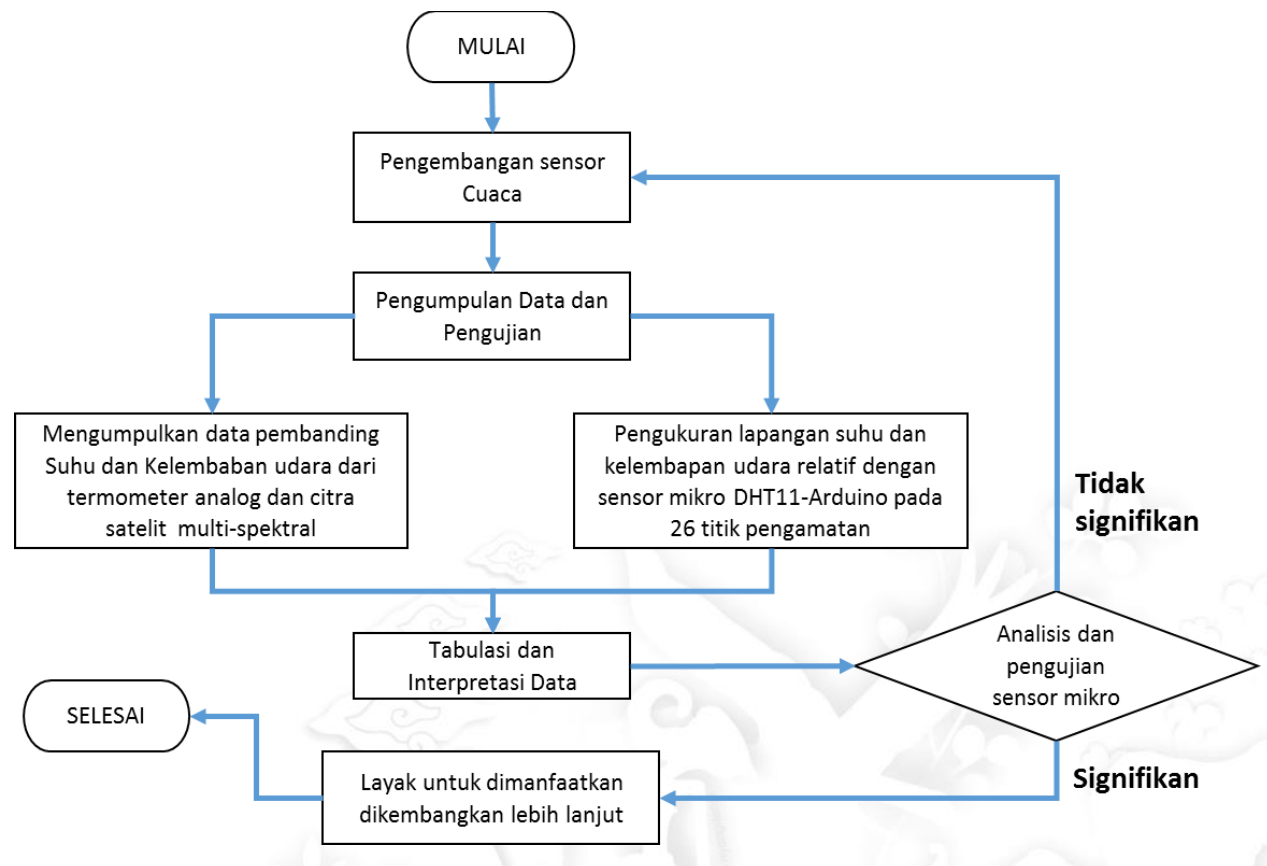

Gambar 2. Skema pengembangan sensor mikro.

Tabel 1. Akuisisi data penelitian.

\begin{tabular}{llll}
\hline Data & Sumber Data & Keterangan \\
\hline Suhu & 1. & DHT11-Arduino & Data primer yang dikumpulkan dengan \\
& 2. & Termometer manual (analog) & DHT11-Arduino dan termometer manual \\
& 3. & Land surface temperature & (analog) pada rentang pukul 13.00-15.00 \\
Kelembaban & 1. & DHT11-Arduino & WIB. Pemilihan waktu ini disesuaikan \\
dengan periode perekaman citra satelit. \\
udara & 2. & Estimasi kelembaban udara & $\begin{array}{l}\text { Sedangkan untuk estimasi kelembaban } \\
\text { udara relatif digunakan algoritma Adab } \text { et }\end{array}$ \\
& & & al (2013).
\end{tabular}

Kerapatan Normalized difference vegetationIndeks ini menggunakan kanal NIR dan vegetasi index kanal merah yang peka terhadap klorofil.

\subsection{Analisis data}

Pada dasarnya, data yang terekam oleh sensor mikro DHT11-Arduino dapat langsung dimanfaatkan karena telah diprogram untuk merekam suhu pada satuan Celsius dan presentase nilai kandungan uap air tiap satu kolom udara (kelembaban udara relatif). Kondisi demikian juga berlaku untuk termometer analog. DHT11 Arduino dan termometer analog memiliki sedikit perbedaan, yakni kemampuan untuk mengukur secara detail hingga level bilangan desimal. DHT11-Arduino tidak mampu mengukur dua angka dibelakang koma, sedangkan sebaliknya mampu dilakukan oleh termometer analog. Meski begitu, DHT11-Arduino memiliki keunggulan komparatif dari segi kemampuannya untuk dapat diintegrasikan dengan IoT. 


$$
\begin{aligned}
& \mathrm{L}_{\lambda}=M_{L} \times Q_{c a l}+A_{L} \\
& \mathrm{~T}=\frac{\mathrm{K}_{2}}{\ln \left(\frac{\mathrm{K}_{1}}{\mathrm{~L}_{\lambda}}+1\right)}
\end{aligned}
$$

dimana $\mathrm{L}_{\lambda}$ merupakan nilai radiasi spektral TOA (top of atmosphere), $\mathrm{M}_{\mathrm{L}}$ sebagai faktor rescaling band termal, $\mathrm{Q}_{\text {cal }}$ besaran energi kalor, $\mathrm{A}_{\mathrm{L}}$ menunjukkan nilai konstanta band termal, $\mathrm{T}$ merupakan nilai suhu dalam satuan Kelvin, dan $\mathrm{K}_{2} / \mathrm{K}_{1}$ sebagai konstanta kalibrasi yang dperoleh dari metadata.

Data pembanding lain untuk suhu diperoleh melalui pemrosesan citra satelit Landsat-8 OLI dengan algoritma Land Surface Temperature (LST) yang didekati melalui radiative transfer equation dan konversi nilai radiasi spektral seperti pada Persamaan 1 dan 2 [13]. Pengukuran LST dari citra satelit Landsat-8 menghasilkan nilai suhu dengan akurasi, distribusi, dan detail yang sangat baik (lihat Tabel 2). Sebelum memasukkan algoritma tersebut, data citra satelit harus melewati tahapan pre-processing agar sesuai dengan kondisi faktual di lapangan dan terbebas dari distorsi atmosfer. Sementara itu, untuk nilai kelembaban udara yang terukur dari sensor mikro DHT11-Arduino dapat dibandingkan dengan nilai estimasi kelembaban udara relatif sesuai dengan algoritma Adab et al pada Persamaan 3 [14]. Pada algoritma tersebut, informasi mengenai tekanan udara diperoleh dari dinamikanya terhadap ketinggian yang berbasis pada DEM SRTM, sedangkan downscaled water vapor merujuk pada hasil pengukuran satelit MODIS Terra / Aqua (MOD05 / MYD05 L2) kanal infra merah jarak dekat (NIR).

$$
\mathrm{RH}=4.03\left\{(-0.001 \mathrm{E}+3.34)^{2}+\left(-0.35 \mathrm{~W}_{\mathrm{d}}+3.04\right)^{2}\right\}
$$

Dimana E merupakan elevasi lahan (meter), $\mathrm{W}_{\mathrm{d}}$ merujuk pada downscaled water vapor $\left(\mathrm{gr} / \mathrm{cm}^{2}\right)$, dan RH menunjukkan kelembaban udara relatif (persen).

Pada kajian ini pengujian mikro sensor DHT11-Arduino dengan data pembanding mengacu pada uji korelasi Spearman Rank (lihat Persamaan 4). Metode ini dipilih karena distribusi data-data tersebut bersifat tidak normal dan diperoleh dengan kaidah purposive sampling [15]. Selain itu, analisis korelasi juga dilakukan secara silang untuk mengetahui hubungan antara suhu dan kelembaban udara relatif di Cikarang Raya. Selengkapnya mengenai skema penelitian tersaji pada Gambar 2.

$$
\rho=\frac{6 \sum d_{i}^{2}}{\mathrm{n}\left(n^{2}-1\right)}
$$

Dimana $\rho$ menunjukkan tingkat korelasi, $\mathrm{n}$ jumlah data yang diamati, dan $\mathrm{d}$ merupakan nilai perbedaan

difference value dari data yang disandingkan. Korelasi dinyatakan signifikan bila $\rho$ hitung $>\rho$ tabel. 


\section{Hasil dan Diskusi}

Suhu di Cikarang Raya hasil pengukuran sensor mikro DHT11-Arduino menunjukkan nilai rata-rata mencapai $34.65{ }^{\circ} \mathrm{C}$ dengan rentang $0.98{ }^{\circ} \mathrm{C}$. Hasil tersebut tidak jauh berbeda dengan hasil pengukuran suhu menggunakan termometer analog yang menunjukkan hasil rata-rata $33.87{ }^{\circ} \mathrm{C}$ dengan rentang $0.96{ }^{\circ} \mathrm{C}$, sedangkan LST menunjukkan suhu rata-rata selama periode pengujian mencapai $35.14{ }^{\circ} \mathrm{C}$ dan rentang $0.89{ }^{\circ} \mathrm{C}$. Bila mengacu pada Tabel 2 terlihat bahwa sensor mikro DHT-11 Arduino memiliki standar deviasi lebih tinggi dibandingkan dua instrumen lainnya, walaupun nilainya masih dapat diterima karena hanya selisih $0.5^{\circ} \mathrm{C}$. Untuk kelembaban udara, mikro sensor DHT11-Arduino menunjukkan nilai rata-rata untuk variabel ini mencapai 42.38 persen dan rentang 5.12 persen. Dari segi distribusinya, terdapat perbedaan dengan nilai kelembaban udara hasil estimasi dengan algoritma Adab et al yang reratanya mencapai 67.01 persen dan rentang 1.88 persen. Meski begitu, baik variabel suhu dan kelembaban yang terukur oleh DHT11-Arduino memiliki pola dan dinamika yang hampir serupa seperti yang ditunjukkan pada Gambar 3.

Tabel 2. Suhu dan kelembaban udara hasil pengukuran multi-instrumen di Cikarang Raya.

\begin{tabular}{llllll}
\hline Instrumen (Variabel) / Koding & Mean & Max. & Min. & S. Dev. & Range \\
\hline DHT11-Arduino (Suhu) $/ \mathrm{T}_{1}$ & 34.65 & 37.00 & 33.00 & 4.00 & 0.98 \\
Termometer analog (Suhu) / $\mathrm{T}_{2}$ & 33.87 & 36.00 & 32.50 & 3.50 & 0.96 \\
Land surface temperature (Suhu) / $\mathrm{T}_{3}$ & 35.14 & 36.98 & 33.37 & 3.60 & 0.89 \\
DHT11-Arduino (Kelembaban udara) $/ \mathrm{H}_{1}$ & 42.38 & 57.00 & 35.00 & 22.00 & 5.12 \\
Algoritma Adab et al (Kelembaban udara) $/ \mathrm{H}_{2}$ & 66.99 & 70.09 & 62.40 & 7.69 & 1.88 \\
\hline
\end{tabular}
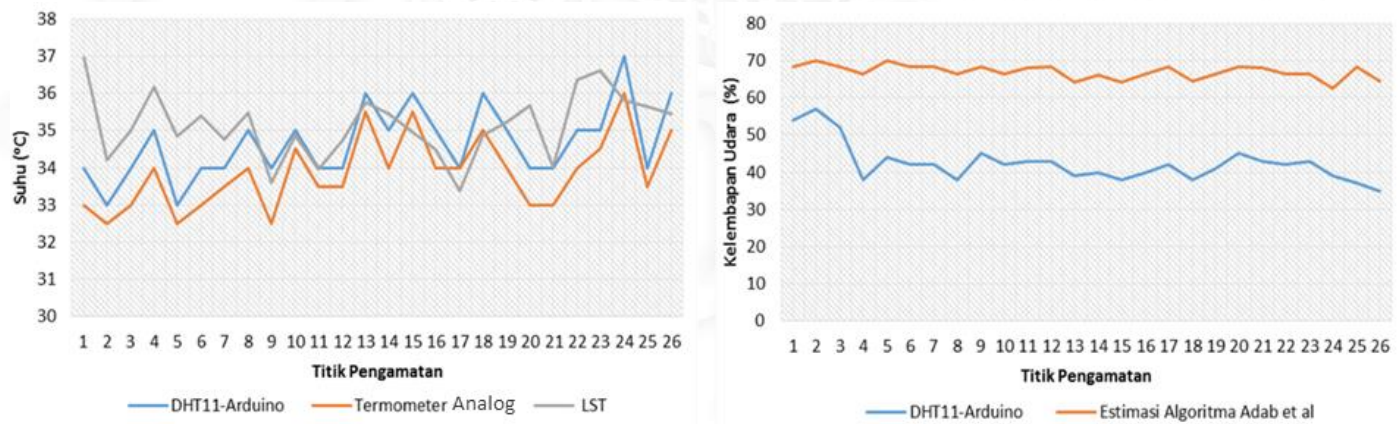

Gambar 3. Komparasi hasil pengukuran suhu (kiri) dan kelembaban udara (kanan) multi-instrumen.

Hasil pengukuran suhu dari berbagai instrumen menunjukkan nilainya berada pada garis yang saling berimpitan dan menandakan adanya pola dinamika yang sama (lihat Lampiran 1). Menariknya terdapat kecenderungan yang hampir sama dari segi polanya antara hasil pengukuran suhu dari mikro sensor dan termometer analog. Sementara untuk kelembaban udara, pengukuran sensor mikro DHT11-Arduino menunjukkan nilai yang lebih dinamis bila dibandingkan dengan estimasi yang berbasis pada data sekunder dari citra satelit. Data pengukuran yang dihasilkan oleh sensor mikro DHT11-Arduino, termometer analog, maupun estimasi citra satelit untuk kedua variabel dapat diolah lebih lanjut untuk memperoleh distribusi spasialnya di Cikarang Raya. Pada kajian ini, seluruh 
isoline (garis atau gradasi warna yang menujukkan distribusi nilai sama) yang dibentuk dari proses interpolasi dan rasterisasi dengan resolusi spasial $15 \times 15$ meter agar sesuai grid atau piksel pada citra Landsat-8 OLI. Metode interpolasi terbaik dari sisi geostatistik untuk data yang persebarannya dan diperoleh secara purposive adalah Kriging karena memiliki galat minimum serta nilai korelasi yang tinggi antara real value dengan estimated value [18].

Interpolasi spasial menunjukkan hasil pengukuran suhu dengan sensor mikro DHT11-Arduino memiliki rata-rata sebesar $34.65{ }^{\circ} \mathrm{C}$, angka tersebut tepat sama dengan data sebelum diinterpolasi (lihat Tabel 3). Bahkan standar deviasi menurun suhu hasil pengukuran instrumen tersebut dinyatakan lebih baik dari termometer analog, meskipun bila melihat nilai rentangnya masih tetap lebih tinggi dari instrumen lainnya - terdapat penurunan sebesar $0.14{ }^{\circ} \mathrm{C}$. Pada variabel kelembaban udara, interpolasi spasial menunjukkan pengukuran dengan sensor mikro DHT11-Arduino memiiki rerata 43.27 persen, sedangkan estimasi dengan algotritma Adab et al reratanya mencapai 67.01. Menariknya penurunan nilai standar deviasi kelembaban udara dialami oleh kedua instrumen, meskipun yang paling tinggi dimiliki oleh DHT11-Arduino sebesar 18.55 persen. Dari pengolahan spasialnya ini menunjukkan, interpolasi Kriging mampu menghasilkan distribusi variabel suhu (isoterm) dan kelembaban udara (isohume) dengan sangat baik berdasarkan data pengukuran pada 26 titik di lapangan (Gambar 4 dan 5).

Tabel 3. Isoterm dan isohume di Cikarang Raya

\begin{tabular}{llllll}
\hline Isolines & Mean & Max. & Min. & S. Dev. & Range \\
\hline Isoterm DHT11-Arduino & 34.65 & 36.88 & 33.02 & 0.66 & 3.86 \\
Isoterm Termometer analog & 33.73 & 35.89 & 32.42 & 0.73 & 3.47 \\
Isoterm LST & 34.95 & 36.85 & 33.38 & 0.63 & 3.47 \\
Isohume DHT11-Arduino & 43.27 & 58.52 & 35.45 & 3.45 & 23.07 \\
Isohume Algoritma Adab et al & 67.01 & 70.05 & 62.64 & 1.28 & 7.41 \\
\hline
\end{tabular}

Tabel 4. Korelasi suhu dan kelembaban udara di Cikarang Raya.

\begin{tabular}{llllll}
\hline Variabel & $\mathbf{T}_{\mathbf{1}}$ & $\mathbf{T}_{\mathbf{2}}$ & $\mathbf{T}_{\mathbf{3}}$ & $\mathbf{H}_{\mathbf{1}}$ & $\mathbf{H}_{\mathbf{2}}$ \\
\hline $\mathbf{T}_{\mathbf{1}}$ & 1 & $0.93^{* *}$ & $0.44^{*}$ & $-0.74^{* *}$ & $-0.94^{* *}$ \\
$\mathbf{T}_{\mathbf{2}}$ & $0.93^{* *}$ & 1 & 0.35 & $-0.75^{* *}$ & $-0.90^{* *}$ \\
$\mathbf{T}_{\mathbf{3}}$ & $0.44^{*}$ & 0.35 & 1 & -0.27 & -0.31 \\
$\mathbf{H}_{\mathbf{1}}$ & $-0.74^{* *}$ & $-0.75^{* *}$ & -0.27 & 1 & $0.69^{* *}$ \\
$\mathbf{H}_{\mathbf{2}}$ & $-0.94^{* *}$ & $-0.90^{* *}$ & -0.31 & $0.69^{* *}$ & 1 \\
\hline
\end{tabular}

${ }^{*}$ Korelasi dengan level signifikansi 0.05 (uji dua sisi).

** Korelasi dengan level signifikansi 0.01 (uji dua sisi).

Dari segi distribusinya pada variabel suhu, hasil pengukuran dengan multi-instrumen menunjukkan suhu tertinggi berada di Kecamatan Cikarang Barat tepatnya pada sisi timur yang berbatasan dengan Kecamatan Cikarang Utara dan Kecamatan Cikarang Selatan. Kondisi berbeda dialami oleh Kecamatan Cikarang Timur yang wilayahnya relatif bersuhu lebih rendah. Bila diperhatikan dengan saksama, distribusi suhu di Cikarang Raya mengindikasikan adanya fenomena urban heat island yang didominasi oleh lahan terbangun, meskipun secara administratif berada pada area rural yang dulunya terkenal sebagai kawasan pertanian - Kabupaten Bekasi [19]. Pada variabel kelembaban udara baik 
yang diukur oleh sensor mikro maupun estimasi algoritma Adab et al, distribusi spasialnya terkonsentrasi pada ujung bagian utara dan barat Kecamatan Cikarang Barat yang diketahui pula sebagai salah satu area dengan suhu terendah di Cikarang Raya. Meski tidak seperti isoterm hasil multi-instrumen yang relatif serupa distribusinya secara spasial, isohume memiliki sedikit perbedaan terutama di sebelah timur Cikarang Raya.

Sensor mikro DHT11-Arduino dinyatakan layak untuk dikembangkan sebagai instrumen untuk mengamati faktor-faktor klimatik. Hasil uji statistik menunjukkan suhu hasil pengukuran menggunakan mikro sensor DHT11-Arduino memiliki korelasi yang signifikan dengan data hasil pengukuran menggunakan termometer analog dan LST, meskipun dengan nilai korelasi dan signifikansi yang berbeda (lihat Tabel 4). DHT11Arduino juga memiliki korelasi yang signifikan dalam mengukur kelembaban udara hasil estimasi dari algoritma Adab et al yakni sebesar 0.69 dengan level signifikansi mencapai 0.01. Selain itu, pengujian ini juga menemukan fakta bahwa suhu dan kelembaban udara memiliki korelasi negatif yang signifikan, terutama antara nilai kelembaban udara hasil pengukuran DHT11-Arduino dengan nilai kelembaban udara hasil estimasi menggunakan algoritme Adab et al yang berbasis pada citra MODIS. Hal ini menandakan semakin rendah suhu akan mengakibatkan kelembaban udara semakin tinggi dan vice versa, karena konsentrasi dimensi kolom udara dipengaruhi oleh suhu [16,17].
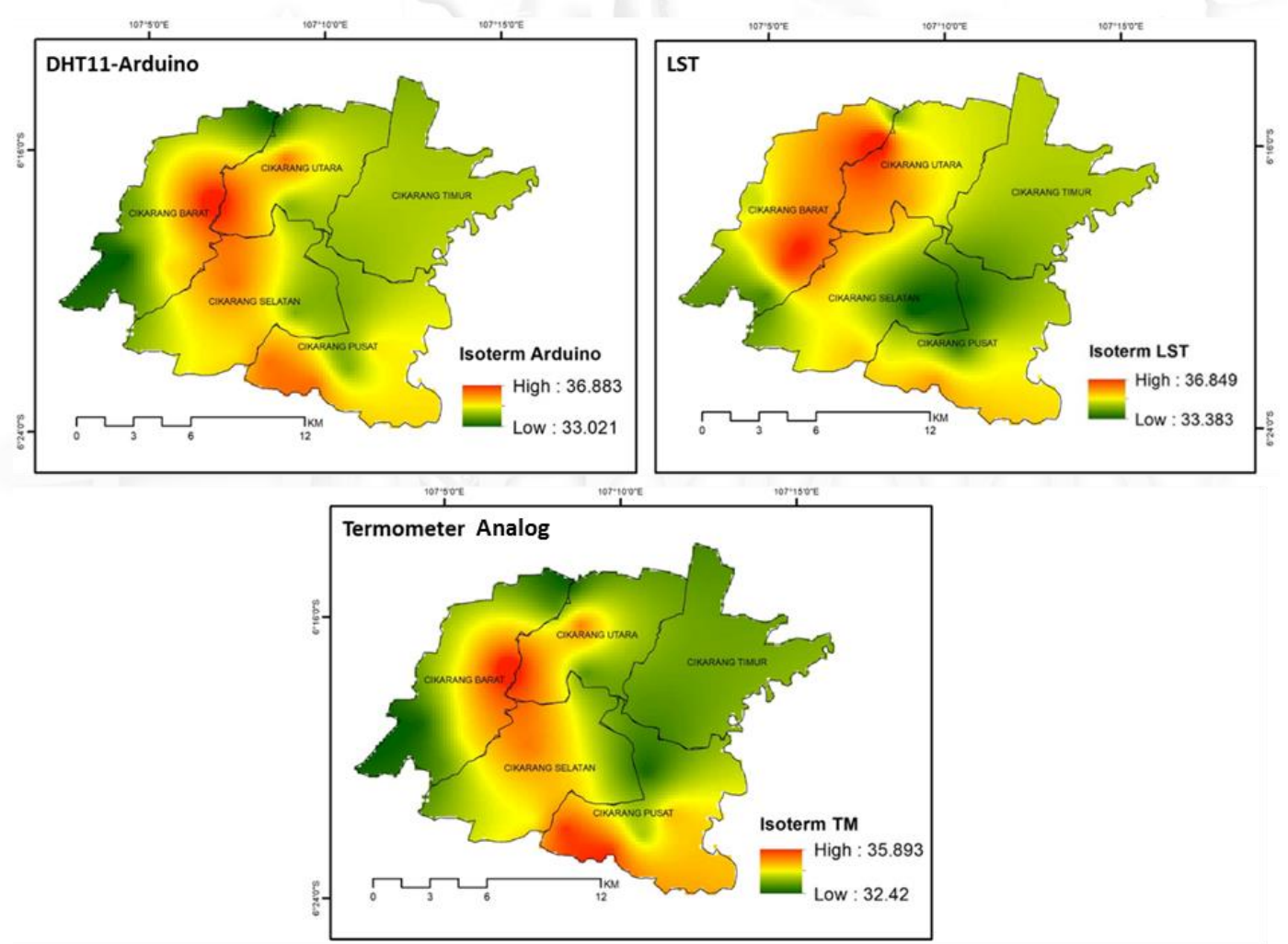

Gambar 4. Isoterm di Cikarang Raya. 

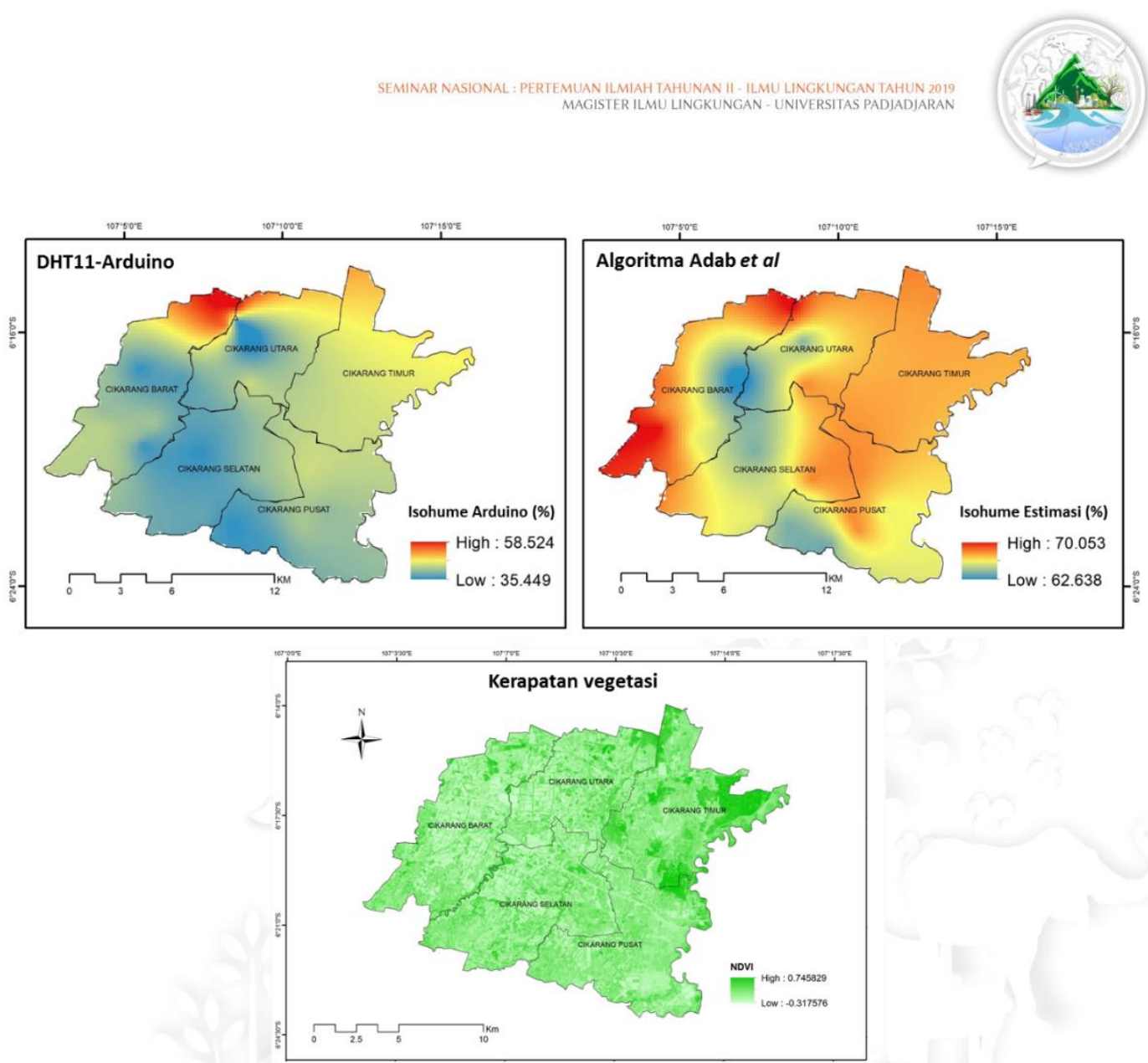

Gambar 5. Isohume dan Kerapatan Vegetasi di Cikarang Raya

\section{Kesimpulan}

Monitoring suhu dan kelembaban udara merupakan salah satu cara untuk memahami ekosistem beserta dinamikanya. Pemerolehan data dan informasi tersebut dapat dilakukan secara efisien dengan memanfaatkan perkembangan teknologi seperti penggunaan sensor mikro DHT11-Arduino. Penelitian ini menunjukkan sensor mikro DHT11-Arduino layak digunakan untuk monitoring suhu dan kelembaban udara dengan hasil yang sangat baik dan dapat dipertanggungjawabkan, hal ini dibuktikan dari pengujian statistik dan komparasi dengan data pembanding yang menunjukkan hasil signifikan. Pengembangan sensor mikro untuk pengamatan faktor-faktor klimatik dapat terus dikembangkan sebagai salah satu metode alternatif pemerolehan data.

\section{Ucapan terimakasih}

Penelitian ini merupakan kerjasama mandiri mahasiswa lintas disiplin (transdisiplin) dan lintas instansi di Kabupaten Bekasi dan Kota Bandung yang terdiri dari Universitas Pelita Bangsa (UPB), Universitas Padjadjaran (UNPAD), Universitas Pendidikan Indonesia (UPI), dan Institut Teknologi Bandung (ITB). Sebagian biaya penelitian ini difasilitasi oleh dana hibah dari PT Tujuh Ion Indonesia pada tahun anggaran 2019. 


\section{Pustaka}

[1] Iskandar J 2018 Ekologi Manusia dan Pembangunan Berkelanjutan. Bandung: Program Studi Magister Ilmu Lingkungan Universitas Padjadjaran.

[2] Dede M, Pramulatsih G P, Widiawaty M A, Ramadhan Y R dan Ati A 2019 Dinamika Suhu Permukaan dan Kerapatan Vegetasi di Kota Cirebon. Jurnal Meteorologi Klimatologi dan Geofisika 6 (1): 23-31. (https://dx.doi.org/ 10.5281/zenodo.3406210).

[3] Kusmingrum N 2018 Potensi Tanaman dalam Menyerap $\mathrm{CO}_{2}$ dan $\mathrm{CO}$ untuk Mengurangi Dampak Pemanasan Global. Jurnal Pemukiman 3 (2): 95-103. (http://doi.org/10.31815/jp.2008.3.96-105)

[4] Widiawaty M A, Dede M dan Ismail A 2018 Analisis Tipologi Urban Sprawl di Kota Bandung Menggunakan Sistem Informasi Geografis. Seminar Nasional Geomatika 3: 547554. (http://dx.doi.org/10.24895/SNG.2018.3-0.1007).

[5] Nandini R dan Narendra B H 2011 Kajian Perubahan Curah Hujan, Suhu dan Tipe Iklim pada Zona Ekosistem di Pulau Lombok. Jurnal Analisis Kebijakan Kehutanan 8 (3): 228244. (https://doi.org/10.20886/jakk.2011.8.3.228-244).

[6] Yani A dan Purwanto B P 2006 Pengaruh Iklim Mikro terhadap Respons Fisiologis Sapi Peranakan Fries Holland dan Modifikasi Lingkungan untuk Meningkatkan Produktivitasnya (ULASAN). Media Peternakan, Media Peternakan 29 (1):35-46.

[7] Sintorini M M 2007 Pengaruh Iklim terhadap Kasus Demam Berdarah Dengue. Kesmas 2 (1): 3-10. (http://dx.doi.org/10.21109/kesmas.v2i1.279).

[8] Tjasyono B dan Syukur M 2013 Keajaiban Planet Bumi dalam Perspektif Sains dan Islam. Bandung: Remaja Rosdakarya. Widiawaty M A 2019 Mari Mengenal Sains Informasi Geografis. Bandung: Aria Mandiri Group. (https:// dx.doi.org/10.31227/osf.io/4s78c).

[9] Widiawaty M A 2019 Mari Mengenal Sains Informasi Geografis. Bandung: Aria Mandiri Group. (https://dx.doi.org/10.31227/osf.io/4s78c).

[10] Beken M, Gunhan H M, Akbulut E dan Çapraz T 2017 Climate Control System For Cold Storage Depots. International Journal of Engineering Science and Application 1 (2): 42-45.

[11] Onokela J dan Othoigbe T O 2015 An Automated Greenhouse Control System Using Arduino Prototyping Platform. Australian Journal of Engineering Research 1 (1): 1-14.

[12] Rossenber, M. (2019). "What are isolines?”. Available https://thought.com/what-areisolines-4068084. [Diakses 30 Agustus 2019]

[13] Tan K C, Lim H S, Jafri M Z M dan Abdullah K 2009 Study on Land Surface Temperature Based on Landsat Image Over Penang Island, Malaysia. Proceeding of Sixth International Conference on Computer Graphics, Imaging and Visualization. IEEE. Tianjin. (https://dx.doi.org/10.1109/CGIV.2009.94)

[14] Adab H, Kanniah K D, Solaimani K, Tan K P 2013 Estimating atmospheric humidity using MODIS cloud-free data in a temperate humid region. IGARSS 2013: 1827-1830.

[15] Setiawan I, Dede M, Sugandi D dan Widiawaty M A 2019 Investigating urban crime pattern and accessibility using geographic information system in Bandung City. KnE Social Sciences 3 (21): 535-548. (https://dx.doi.org/10.18502/kss.v3i21.4993)

[16] Nguyen J L dan Dockery D W 2016 Daily indoor-to-outdoor temperature and humidity relationships: a sample across seasons and diverse climatic regions. International Journal Biometeorol 60 (2): 221-229.

[17] Yousif T A dan Tahir H M M 2013 The Relationship between Relative Humidity and the Dew point Temperature in Khartoum State, Sudan. Journal of Applied and Industrial Sciences 1 (5): 20-23.

[18] Widiawaty M A, Dede M dan Ismail I 2018 Kajian komparatif pemodelan air tanah menggunakan sistem informasi geografis di Desa Kayuambon, Kabupaten Bandung Barat. Jurnal Geografi Gea 18 (1): 63-71. (https://dx.doi.org/10.17509/gea.v18i1.10397)

[19] Dede M, Sewu R S B, Yutika M dan Ramadhan F 2016 Analisis potensi perekonomian sektor pertanian, kehutanan, dan perikanan serta pertambangan dan penggalian di Pantura Jawa Barat. Seminar Nasional Epicentrum $5.5 \quad 1 \quad$ (1): 100-108. (https://dx.doi.org/10.31227/osf.io/mc2td) 
Lampiran 1. Rincian hasil pengukuran suhu dan kelembaban multi-instrumen.

\begin{tabular}{|l|l|l|l|l|l|}
\hline \multirow{2}{*}{ Plot } & \multicolumn{2}{|l|}{ Suhu $\left({ }^{\mathbf{}} \mathbf{C}\right)$} & $\begin{array}{l}\text { Termometer } \\
\text { Analog }\end{array}$ & LST & Kelembaban Udara $(\%)$ \\
\cline { 2 - 6 } & DHT11-Arduino & 33 & 36.98 & 54 & Adab et al \\
\hline 1 & 34 & 32.5 & 34.21 & 57 & 68.32 \\
\hline 2 & 33 & 33 & 35.00 & 52 & 70.09 \\
\hline 3 & 34 & 34 & 36.16 & 38 & 68.33 \\
\hline 4 & 35 & 32.5 & 34.85 & 44 & 66.36 \\
\hline 5 & 33 & 33 & 35.39 & 42 & 70.01 \\
\hline 6 & 34 & 33.5 & 34.77 & 42 & 68.23 \\
\hline 7 & 34 & 34 & 35.48 & 38 & 68.28 \\
\hline 8 & 35 & 32.5 & 33.60 & 45 & 66.43 \\
\hline 9 & 34 & 34.5 & 34.87 & 42 & 68.25 \\
\hline 10 & 35 & 33.5 & 33.97 & 43 & 66.33 \\
\hline 11 & 34 & 33.5 & 34.73 & 43 & 68.18 \\
\hline 12 & 34 & 35.5 & 35.74 & 39 & 68.21 \\
\hline 13 & 36 & 34 & 35.45 & 40 & 64.27 \\
\hline 14 & 35 & 35.5 & 34.96 & 38 & 66.24 \\
\hline 15 & 36 & 34 & 34.47 & 40 & 64.31 \\
\hline 16 & 35 & 34 & 33.37 & 42 & 66.39 \\
\hline 17 & 34 & 35 & 34.87 & 38 & 68.27 \\
\hline 18 & 36 & 34 & 35.24 & 41 & 64.35 \\
\hline 19 & 35 & 33 & 35.69 & 45 & 66.4 \\
\hline 20 & 34 & 33 & 34.01 & 43 & 68.3 \\
\hline 21 & 34 & 34 & 36.35 & 42 & 68.19 \\
\hline 22 & 35 & 34.5 & 36.62 & 43 & 66.32 \\
\hline 23 & 35 & 36 & 35.82 & 39 & 66.36 \\
\hline 24 & 37 & 33.5 & 35.64 & 37 & 62.4 \\
\hline 25 & 34 & 35 & 35.44 & 35 & 64.51 \\
\hline 26 & 36 & & & & \\
\hline
\end{tabular}


Lampiran 2. Data kontinu hasil pengukuran sensor DHT11-Arduino

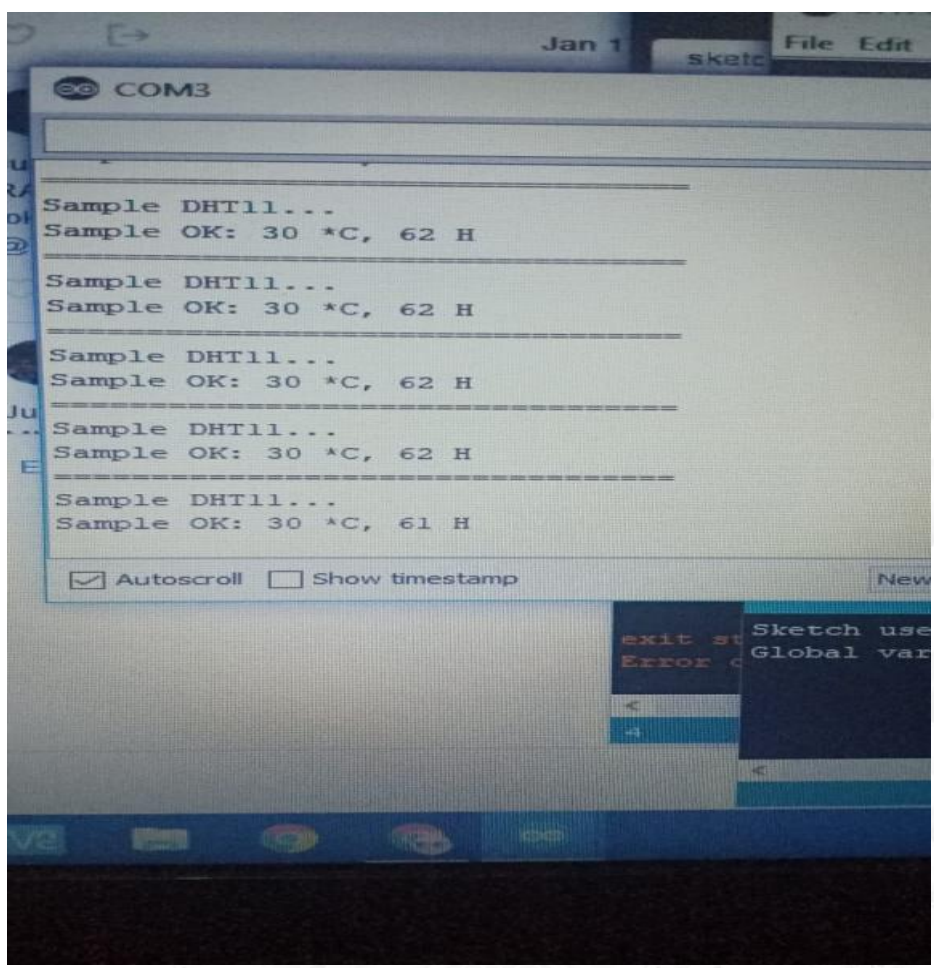


Lampiran 3. Blok diagram skema peralatan sensor mikro DHT11-Arduino

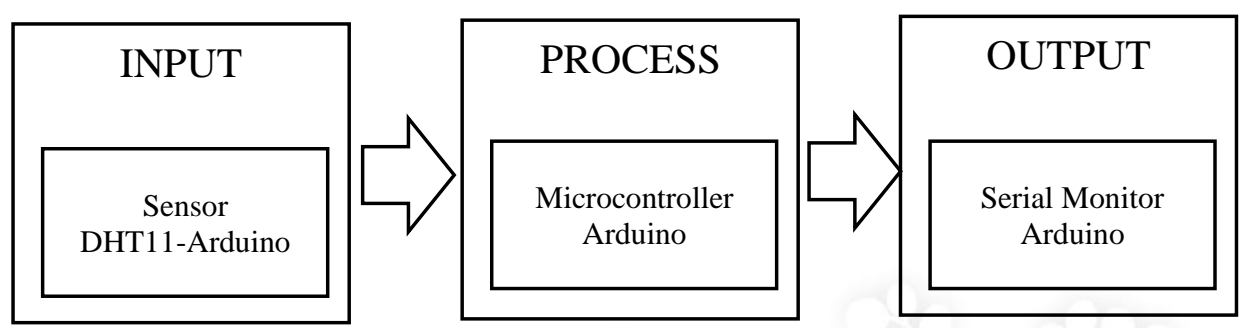

